Published in final edited form as:

N Engl J Med. 2014 June 19; 370(25): 2367-2376. doi:10.1056/NEJMoa1401811.

\title{
Antimicrobial Prophylaxis for Children with Vesicoureteral Reflux
}

\section{The RIVUR Trial Investigators ${ }^{\star}$}

\begin{abstract}
BACKGROUND—Children with febrile urinary tract infection commonly have vesicoureteral reflux. Because trial results have been limited and inconsistent, the use of antimicrobial prophylaxis to prevent recurrences in children with reflux remains controversial.

METHODS-In this 2-year, multisite, randomized, placebo-controlled trial involving 607 children with vesicoureteral reflux that was diagnosed after a first or second febrile or symptomatic urinary tract infection, we evaluated the efficacy of trimethoprim-sulfamethoxazole prophylaxis in preventing recurrences (primary outcome). Secondary outcomes were renal scarring, treatment failure (a composite of recurrences and scarring), and antimicrobial resistance.
\end{abstract}

RESULTS-Recurrent urinary tract infection developed in 39 of 302 children who received prophylaxis as compared with 72 of 305 children who received placebo (relative risk, $0.55 ; 95 \%$ confidence interval [CI], 0.38 to 0.78 ). Prophylaxis reduced the risk of recurrences by $50 \%$ (hazard ratio, $0.50 ; 95 \% \mathrm{CI}, 0.34$ to 0.74 ) and was particularly effective in children whose index infection was febrile (hazard ratio, $0.41 ; 95 \% \mathrm{CI}, 0.26$ to 0.64 ) and in those with baseline bladder and bowel dysfunction (hazard ratio, $0.21 ; 95 \% \mathrm{CI}, 0.08$ to 0.58 ). The occurrence of renal scarring did not differ significantly between the prophylaxis and placebo groups (11.9\% and $10.2 \%$, respectively). Among 87 children with a first recurrence caused by Escherichia coli, the proportion of isolates that were resistant to trimethoprim-sulfamethoxazole was $63 \%$ in the prophylaxis group and $19 \%$ in the placebo group.

Copyright @ 2014 Massachusetts Medical Society.

Address reprint requests to Dr. Hoberman at Children's Hospital of Pittsburgh, General Academic Pediatrics, 3414 Fifth Ave., CHOB 3rd Fl., Rm. 321, Pittsburgh, PA 15213, or at hoberman@chp.edu.

${ }^{*}$ A complete list of the Randomized Intervention for Children with Vesicoureteral Reflux (RIVUR) trial investigators is provided in the Supplementary Appendix, available at NEJM.org.

Members of the writing group (Alejandro Hoberman, M.D., Children's Hospital of Pittsburgh of University of Pittsburgh Medical Center, Pittsburgh; Saul P. Greenfield, M.D., Women and Children's Hospital of Buffalo, Buffalo, NY; Tej K. Mattoo, M.D., Wayne State University School of Medicine, Detroit; Ron Keren, M.D., M.P.H., Children's Hospital of Philadelphia, Philadelphia; Ranjiv Mathews, M.D., Johns Hopkins School of Medicine, Baltimore; Hans G. Pohl, M.D., Children's National Medical Center,

Washington, DC; Bradley P. Kropp, M.D., University of Oklahoma Health Sciences Center, Oklahoma City; Steven J. Skoog, M.D., Oregon Health and Science University, Portland; Caleb P. Nelson, M.D., M.P.H., Boston Children's Hospital, Boston; Marva MoxeyMims, M.D., National Institute of Diabetes and Digestive and Kidney Diseases, Bethesda, MD; Russell W. Chesney, M.D., Le Bonheur Children's Hospital, Memphis, TN; and Myra A. Carpenter, Ph.D., University of North Carolina at Chapel Hill, Chapel Hill) assume responsibility for the content of this article.

The content of this report is solely the responsibility of the authors and does not necessarily represent the official views of the National Institute of Diabetes and Digestive and Kidney Diseases (NIDDK) or the National Institutes of Health (NIH).

Dr. Hoberman reports receiving fees for providing expert testimony in a legal case involving neonatal hypoglycemia. No other potential conflict of interest relevant to this article was reported.

Disclosure forms provided by the authors are available with the full text of this article at NEJM.org. 
CONCLUSIONS-Among children with vesicoureteral reflux after urinary tract infection, antimicrobial prophylaxis was associated with a substantially reduced risk of recurrence but not of renal scarring. (Funded by the National Institute of Diabetes and Digestive and Kidney Diseases and others; RIVUR ClinicalTrials.gov number, NCT00405704.)

Vesicoureteral reflux is present in one third of children presenting with febrile urinary tract infection and has been associated with a heightened risk of renal scarring. ${ }^{1}$ Early randomized, controlled trials that compared antireflux surgery with antimicrobial prophylaxis showed no significant differences in the rates of recurrent urinary tract infection (recurrences) and renal scarring ${ }^{2-5}$; however, the lack of a placebo or observation group precluded a determination that either surgery or prophylaxis was effective. More recent randomized trials, most of which were unblinded, have had conflicting results regarding the effectiveness of anti-microbial prophylaxis in reducing recurrences. ${ }^{6-11} \mathrm{We}$ designed the Randomized Intervention for Children with Vesicoureteral Reflux (RIVUR) trial to determine whether long-term antimicrobial prophylaxis is effective in preventing febrile or symptomatic recurrences and reducing the likelihood of renal scarring, and the extent to which it contributes to bacterial resistance.

\section{METHODS}

\section{STUDY DESIGN AND OVERSIGHT}

The study was a randomized, double-blind, placebo-controlled trial of prophylaxis with trimethoprim-sulfamethoxazole (Sulfatrim Pediatric suspension from Actavis and Sulfamethoxazole and Trimethoprim Oral Suspension from Hi-Tech Pharmacal) in children with vesicoureteral reflux that was diagnosed after a first or second febrile or symptomatic urinary tract infection (index infection). The project steering committee designed the trial, which was sponsored by the National Institute of Diabetes and Digestive and Kidney Diseases (NIDDK) and was conducted under an Investigational New Drug application (number 75,739) to the Food and Drug Administration. The study rationale and design have been published previously, ${ }^{12-16}$ and the protocol is available with the full text of this article at NEJM.org. The writing group wrote the manuscript and vouches for the completeness and accuracy of the data and analyses and the fidelity of the study to the protocol.

We enrolled children at 19 clinical sites across the United States who were 2 to 71 months of age and had grade I to IV vesicoureteral reflux. We excluded children whose index infection occurred more than 112 days before randomization and children with coexisting urologic anomalies, contraindications for the use of trimethoprim-sulfamethoxazole, or certain medical conditions (see the Supplementary Appendix, available at NEJM.org). We followed the children for 2 years to ascertain the primary outcome of febrile or symptomatic recurrence and secondary outcomes of renal scarring, failure of prophylaxis, and antimicrobial resistance. We also assessed bladder and bowel dysfunction according to a standardized measure (see the Supplementary Appendix). ${ }^{12,17,18}$ An NIDDK data and safety monitoring board and an institutional review board at each site approved the protocol. Parents or legal guardians of the children provided written informed consent before enrollment. 


\section{RANDOMIZATION}

Randomization was performed in permuted blocks, stratified according to site. Data management and statistical analyses were performed by a data-coordinating center at the University of North Carolina at Chapel Hill. We randomly assigned children to receive daily trimethoprim-sulfamethoxazole suspension ( $3 \mathrm{mg}$ of trimethoprim plus $15 \mathrm{mg}$ of sulfamethoxazole per kilogram of body weight) or placebo (prepared by UPM Pharmaceuticals) that was nearly identical in color, smell, taste, and consistency. Four persons at the data-coordinating center managed the linkage of study-group assignments with study medications; the data-management software confirmed the eligibility of each child and generated assignments to coded bottles of study medication.

\section{STUDY PROCEDURES}

Urine specimens from children who were not toilet trained were obtained by means of catheterization or suprapubic aspiration; bag-collected specimens were not permitted. Clean, voided specimens were collected from toilet-trained children. Index and outcome infections met stringent diagnostic criteria that included evidence of pyuria on urinalysis, cultureproven infection, and fever $\left(38^{\circ} \mathrm{C}\right)$ or urinary tract symptoms within 24 hours before or after urine collection. ${ }^{12,14}$ Renal scanning with technetium-99m-labeled dimercaptosuccinic acid was performed at baseline and after 1 and 2 years. Two pediatric nuclear-medicine physicians assessed the extent of renal cortical defects semiquantitatively by dividing the cortex into 12 segments and determined severity on the basis of the number of segments affected. Treatment failure was defined as two febrile recurrences, one febrile and three symptomatic recurrences, or four symptomatic recurrences over the course of the study or as new or worsening scarring at 1 year. ${ }^{14}$

At baseline, after the occurrence of treatment failure, and at 24 months, we obtained rectal swabs, which were tested in a central laboratory for resistance of Escherichia coli isolates to trimethoprim-sulfamethoxazole. ${ }^{19} \mathrm{We}$ also assessed, at local laboratories, resistance among pathogens identified in children with recurrences.

\section{STATISTICAL ANALYSIS}

We estimated that a sample of 300 children in each study group would provide at least $80 \%$ power to detect a reduction in the proportion of children with febrile or symptomatic recurrences during a 2-year follow-up period from $20 \%$ in the placebo group to $10 \%$ in the trimethoprim-sulfamethoxazole group, at a two-sided alpha level of 0.05 . Our a priori plan called for an intention-to-treat analysis of recurrences, stratified according to site, with the use of a Cochran-Mantel-Haenszel test with missing outcomes imputed as events, as well as time-to-event analyses with the use of a stratified log-rank test. We used Kaplan-Meier estimates to describe the proportions of children who had febrile or symptomatic recurrences or who met the criteria for treatment failure. We used Cox models both in analyses of treatment effects according to age, sex, severity of reflux, and other factors and in analyses that were controlled for multiple factors. We used Fisher's exact test to compare adverse events in the two study groups. Reported $\mathrm{P}$ values have not been adjusted for multiple comparisons; a P value of less than 0.046 was considered to indicate statistical significance for the primary outcome. Sensitivity analyses of febrile or symptomatic recurrences were 
performed, first, by including children for whom outcome data were missing and classifying them as not having had an event and, second, by omitting such children from the analyses.

\section{RESULTS \\ STUDY PARTICIPANTS}

We screened and enrolled children between June 2007 and May 2011; however, capture of screening data began in November 2007. Of 10,871 children with screening data available, $1426(13.1 \%)$ met the eligibility criteria, of whom 607 (42.6\%) were enrolled. For 115 of the 607 children enrolled who met all the eligibility criteria in the course of the study, corresponding screening data for those not enrolled were not available (Fig. 1). Follow-up was completed in June 2013. Baseline demographic and clinical characteristics of the trial participants have been reported previously. ${ }^{12}$ Briefly, 554 children (91.3\%) were enrolled after their first urinary tract infection; the index infection was febrile in 521 children (85.8\%). The median age was 12 months, and 558 (91.9\%) of the children were girls. A total of 484 of 602 children (80.4\%) had grade II or III vesicoureteral reflux; 287 of 600 children (47.8\%) had bilateral reflux. Of 126 toilet-trained children, 71 (56.3\%) had symptoms of bladder and bowel dysfunction. No significant differences in sex, race, or ethnic group were apparent between enrolled children and those who were screened but not enrolled. The study groups did not differ significantly with respect to any baseline characteristic (Table 1).

\section{ADHERENCE}

Parents of 467 of the children (76.9\%) reported having administered the study medication at least $75 \%$ of the time, and parents of 517 children $(85.2 \%)$ reported having administered it at least $50 \%$ of the time. Parents of 91 children in the prophylaxis group and of 76 children in the placebo group discontinued the study medication. No significant difference in reported adherence to the study-medication regimen was noted between the study groups.

\section{RECURRENCES OF FEBRILE OR SYMPTOMATIC URINARY TRACT INFECTION}

During the trial, 111 children had 171 recurrences of urinary tract infection (Table 2, and Table S1 in the Supplementary Appendix). Of 111 first recurrences, 80 (72.1\%) were febrile; 2 first recurrences took place after 24 months but before the study exit visit. The risk of febrile or symptomatic recurrences was reduced by half among children who received prophylaxis as compared with those who received placebo, and the difference between the two groups widened progressively over time (hazard ratio, $0.50 ; 95 \%$ confidence interval [CI], 0.34 to 0.74 ) (Fig. 2 and 3). The interval between enrollment and a $10 \%$ incidence of recurrence was 336 days in the prophylaxis group and 106 days in the placebo group. Eight children (95\% CI, 5 to 16) would have had to be treated for 2 years to prevent one case of febrile or symptomatic urinary tract infection.

In our primary intention-to-treat analysis with the assumption that children with missing primary-outcome data had had an event, a significantly smaller proportion of children who received prophylaxis, as compared with those who received placebo, had a febrile or symptomatic recurrence ( $25.5 \%$ vs. $37.4 \%$; relative risk, $0.68 ; 95 \% \mathrm{CI}, 0.53$ to 0.87 ) (Table 2). Similar results were obtained from sensitivity analyses that included children with 
missing outcome data but assumed they had not had an event (12.8\% vs. $25.4 \%$; relative risk, 0.55 ; $95 \% \mathrm{CI}, 0.38$ to 0.78 ) and that omitted children for whom primary-outcome data were missing ( $14.8 \%$ vs. $27.4 \%$; relative risk, $0.54 ; 95 \%$ CI, 0.38 to 0.77$)$. The proportion of children meeting the criteria for treatment failure in the placebo group was nearly twice the proportion in the prophylaxis group (9.6\% vs. $5.0 \%, \mathrm{P}=0.035)$. In separate Cox models, the study-group effect remained unchanged after we controlled for age, whether the index urinary tract infection was the child's first or second episode, the degree of baseline reflux, and the presence or absence of baseline renal scarring (Table S2 in the Supplementary Appendix).

\section{RENAL SCARRING}

As reported previously, ${ }^{12}$ a total of 98 of 582 baseline scans were obtained less than 31 days after the index infection (16.8\%), and 484 were obtained between 31 and 112 days after the index infection (83.2\%). A total of 21 scans (3.6\%) were interpreted as indicating renal scarring, and $71(12.2 \%)$ were interpreted as indicating acute pyelonephritis. Outcome scans (at the 2-year visit or 3 to 4 months after the child had met treatment-failure criteria) showed no significant between-group differences in the incidence of renal scarring (11.9\% in the prophylaxis group and $10.2 \%$ in the placebo group, $\mathrm{P}=0.55)$, severe renal scars $(4.0 \%$ and $2.6 \%$, respectively; $\mathrm{P}=0.37$ ), or new renal scars since baseline ( $8.2 \%$ and $8.4 \%$, respectively; $\mathrm{P}=0.94)($ Table 2$)$.

\section{ANTIMICROBIAL RESISTANCE}

Stool colonization with resistant $E$. coli was more common in the prophylaxis group than in the placebo group, but the difference was not significant (Table 2). Among 87 children with a first febrile or symptomatic recurrence with $E$. coli, the proportion of isolates that were resistant to trimethoprim-sulfamethoxazole was $63 \%$ with prophylaxis and $19 \%$ with placebo $(\mathrm{P}<0.001)$.

\section{EFFECT MODIFIERS}

Children with grade III or IV reflux at baseline were more likely to have febrile or symptomatic recurrences than were children with grade I or II reflux (64 of 280 children [22.9\%] vs. 46 of 322 [14.3\%], P = 0.003). Hazard ratios for recurrences consistently favored the prophylaxis group, irrespective of sex, age at study entry, degree of reflux, whether children had one or two urinary tract infections before enrollment, whether the index infection was caused by a resistant pathogen, and whether reflux present at baseline had resolved, improved, not changed, or worsened at 2 years (Fig. 3). There were significant interactions between study group and the type of index infection $(\mathrm{P}=0.04)$ and between study group and the presence or absence of bladder and bowel dysfunction at baseline $(\mathrm{P}=$ 0.02 ). The estimated hazard ratio for a febrile or symptomatic recurrence in the prophylaxis group relative to the placebo group was 0.41 (95\% CI, 0.26 to 0.64 ) among children with a febrile index infection and 1.28 (95\% CI, 0.47 to 3.46) among children with a nonfebrile index infection. Corresponding hazard ratios for children with and those without bladder and bowel dysfunction at baseline were 0.21 (95\% CI, 0.08 to 0.58 ) and 1.40 (95\% CI, 0.43 to 
4.58). The study population included too few boys to evaluate the effect of circumcision, but all four boys with a first recurrence were uncircumcised at baseline.

\section{REFLUX STATUS AT 2 YEARS}

Voiding cystourethrography was performed at 2 years in 428 children. Reflux was considered to be resolved in 218 children (50.9\%), improved in 100 (23.4\%), unchanged in $79(18.5 \%)$, and worse in $31(7.2 \%)$.

\section{ADVERSE EVENTS}

We found no significant between-group differences in the proportions of children with fever (14.2\% in the prophylaxis group and $18.0 \%$ in the placebo group, $\mathrm{P}=0.23$ ), otitis media ( $4.3 \%$ and $7.9 \%$, respectively; $\mathrm{P}=0.09$ ), diarrhea ( $3.6 \%$ and $6.2 \%, \mathrm{P}=0.19)$, pharyngitis (6.3\% and $4.6 \%, \mathrm{P}=0.38)$, rash $(7.6 \%$ and $7.5 \%, \mathrm{P}=1.0)$, or viral infection $(4.6 \%$ and $5.2 \%, \mathrm{P}=0.85$ ) (Table S3 in the Supplementary Appendix). Hospitalizations or emergency room visits also did not differ significantly between the prophylaxis and placebo groups (41.1\% and 48.5\%, respectively; P = 0.06) (Table S4 in the Supplementary Appendix).

\section{DISCUSSION}

Antimicrobial prophylaxis in children with vesicoureteral reflux diagnosed after a first or second urinary tract infection was associated with a halving of the risk of febrile or symptomatic recurrences. Differences between the prophylaxis and placebo groups were apparent early on and increased over a 2-year period. Children with bladder and bowel dysfunction at baseline and children whose index infection was febrile derived particular benefit from prophylaxis, with reductions in recurrences of approximately $80 \%$ and $60 \%$, respectively. Rates of renal scarring at the outcome visit were low and were not reduced by prophylaxis, perhaps because most children were enrolled after their first infection and because parents, who were instructed to be vigilant, sought early medical attention. Not unexpectedly, recurrences that did occur in children who received prophylaxis were more likely to have been caused by a resistant pathogen.

We designed our trial to avoid certain limitations of previous studies. ${ }^{2-11,20} \mathrm{We}$ enrolled, from a variety of clinical settings, a large, representative sample of children with vesicoureteral reflux (grade I to IV) that was diagnosed after a urinary tract infection. We applied stringent diagnostic criteria and used standardized scales to identify predisposing factors. ${ }^{12}$ Our radiologists applied standardized criteria to enhance the reliability of their interpretations of urinary tract images. ${ }^{15,16}$ Our trial has certain limitations: our results may not be applicable to children with different demographic or clinical characteristics or children in locales where the choice of trimethoprim-sulfamethoxazole may be limited by susceptibility patterns or clinical acceptability, and some of our subgroup analyses had limited statistical power.

There are both similarities and differences between our findings and those of two other trials. ${ }^{10,20}$ Craig et al. enrolled 576 Australian children under the age of 18 years with stringently defined urinary tract infection in a placebo-controlled trial of trimethoprimsulfamethoxazole prophylaxis. ${ }^{10}$ Sixty-four percent of the children were girls. Twelve 
months of prophylaxis was associated with a reduction in the absolute risk of symptomatic recurrences of 6 percentage points (number needed to treat, 14). However, pyuria was not found at the index infection in $32 \%$ of the children, only $42 \%$ of the children had reflux, $41 \%$ had normal voiding studies, $17 \%$ did not undergo voiding cystourethrography, and renal scanning with technetium-99m-labeled dimercaptosuccinic acid was performed after 1 year in only $27 \%$ of the children. In our trial, all children were younger than 6 years of age, $92 \%$ were girls, all were considered to have grade I to IV reflux, the diagnosis of infection required the presence of pyuria, renal scanning was performed after 2 years in $76 \%$ of the children, and the effect of prophylaxis was sustained over a 2 -year period (number needed to treat, 8).

Brandström et al. randomly assigned 203 Swedish children 12 to 23 months of age with grade III or IV reflux to receive antimicrobial prophylaxis (with trimethoprim, nitrofurantoin, or cefadroxil), endoscopic treatment, or surveillance only. ${ }^{20}$ A total of $37 \%$ of the participants were boys, most of whom were uncircumcised. Clinicians and parents were aware of the studygroup assignments, and bag-collected urine specimens were permitted. Significant differences in outcome were noted only in girls. Girls in the surveillance-only group had the highest incidence of febrile recurrence and the shortest time to a first recurrence; girls who received antimicrobial prophylaxis had the lowest incidence of renal scarring at 2 years of follow-up. ${ }^{21}$

Do our results support recent recommendations regarding urinary tract imaging in children with a first febrile urinary tract infection ${ }^{22}$ Many factors may influence that decision in individual children, including the presence or absence of a family history of vesicoureteral reflux, age, sex, and race, which affect the probability that vesicoureteral reflux is present; the severity of the clinical course of the infection; the status of bladder and bowel function; the cost of voiding cystourethrography and associated discomfort; the importance that parents place on preventing recurrences (which sometimes result in alarming symptoms, hospitalization, and parental work loss and which may influence the decision to proceed to surgery in children found to have reflux); perceived parental ability to adhere to a prophylaxis regimen; parental concern about potential long-term effects of prophylaxis, such as the development of antimicrobial resistance and alterations of the microbiome; and most important, the effectiveness of prophylaxis in preventing recurrences.

As long as evidence supporting the benefit of prophylaxis was dubious, the recommendation of a watchful-waiting approach, without performance of a voiding cystourethrographic study, ${ }^{22}$ seemed reasonable, because the imaging findings would not affect the nature of treatment. However, our finding that antimicrobial prophylaxis was associated with a reduced risk of recurrence may warrant reconsideration of that recommendation. Decision analysis and cost-effectiveness analysis may help to clarify the clinical and financial tradeoffs, which may help clinicians and families reach more informed decisions about the advisability of imaging in young children such as those in our study.

\section{Supplementary Material}

Refer to Web version on PubMed Central for supplementary material. 


\section{Acknowledgments}

Supported by grants from the NIDDK, NIH (U01 DK074059, U01 DK074053, U01 DK074082, U01 DK074064, U01 DK074062, and U01 DK074063); and by Clinical and Translational Science Awards from the National Center for Research Resources, now at the National Center for Advancing Translational Sciences, NIH (UL1RR024153 and UL1TR000005, to the University of Pittsburgh; and UL1TR000003, to the Children's Hospital of Philadelphia).

We thank Jack L. Paradise, M.D., for editorial suggestions; and the study participants, their families, and participating physicians, investigators, and staff for making this research possible.

\section{References}

1. Hoberman A, Charron M, Hickey RW, Baskin M, Kearney DH, Wald ER. Imaging studies after a first febrile urinary tract infection in young children. N Engl J Med. 2003; 348:195-202. [PubMed: 12529459]

2. Medical versus surgical treatment of primary vesicoureteral reflux: report of the International Reflux Study Committee. Pediatrics. 1981; 67:392-400. [PubMed: 7017578]

3. Birmingham Reflux Study Group. Prospective trial of operative versus non-operative treatment of severe vesicoureteric reflux in children: five years' observation. Br Med J (Clin Res Ed). 1987; 295:237-41.

4. Smellie JM, Barratt TM, Chantler C, et al. Medical versus surgical treatment in children with severe bilateral vesicoureteric reflux and bilateral nephropathy: a randomised trial. Lancet. 2001; 357:1329-33. [PubMed: 11343739]

5. Weiss R, Duckett J, Spitzer A. Results of a randomized clinical trial of medical versus surgical management of infants and children with grades III and IV primary vesicoureteral reflux (United States). J Urol. 1992; 148:1667-73. [PubMed: 1433585]

6. Garin EH, Olavarria F, Garcia Nieto V, Valenciano B, Campos A, Young L. Clinical significance of primary vesicoureteral reflux and urinary antibiotic prophylaxis after acute pyelonephritis: a multicenter, randomized, controlled study. Pediatrics. 2006; 117:626-32. [PubMed: 16510640]

7. Roussey-Kesler G, Gadjos V, Idres N, et al. Antibiotic prophylaxis for the prevention of recurrent urinary tract infection in children with low grade vesicoureteral reflux: results from a prospective randomized study. J Urol. 2008; 179:674-9. [PubMed: 18082208]

8. Pennesi M, Travan L, Peratoner L, et al. Is antibiotic prophylaxis in children with vesicoureteral reflux effective in preventing pyelonephritis and renal scars? A randomized, controlled trial. Pediatrics. 2008; 121(6):e1489-e1494. [PubMed: 18490378]

9. Montini G, Rigon L, Zucchetta P, et al. Prophylaxis after first febrile urinary tract infection in children? A multicenter, randomized, controlled, noninferiority trial. Pediatrics. 2008; 122:1064-71. [PubMed: 18977988]

10. Craig JC, Simpson JM, Williams GJ, et al. Antibiotic prophylaxis and recurrent urinary tract infection in children. N Engl J Med. 2009; 361:1748-59. Erratum, N Engl J Med 2010;362:1250. [PubMed: 19864673]

11. Hoberman A, Keren R. Antimicrobial prophylaxis for urinary tract infection in children. N Engl J Med. 2009; 361:1804-6. [PubMed: 19864680]

12. Carpenter MA, Hoberman A, Mattoo TK, et al. The RIVUR trial: profile and baseline clinical associations of children with vesicoureteral reflux. Pediatrics. 2013; 132(1):e34-e45. [PubMed: 23753091]

13. Chesney RW, Carpenter MA, Moxey-Mims M, et al. Randomized Intervention for Children With Vesicoureteral Reflux (RIVUR): background commentary of RIVUR investigators. Pediatrics. 2008; 122(Suppl 5):S233-S239. [PubMed: 19018047]

14. Keren R, Carpenter MA, Hoberman A, et al. Rationale and design issues of the Randomized Intervention for Children With Vesicoureteral Reflux (RIVUR) study. Pediatrics. 2008; 122(Suppl 5):S240-S250. [PubMed: 19018048] 
15. Greenfield SP, Carpenter MA, Chesney RW, Zerin JM, Chow J. The RIVUR voiding cystourethrogram pilot study: experience with radiologic reading concordance. J Urol. 2012; 188(Suppl):1608-12. [PubMed: 22910235]

16. Ziessman HA, Majd M. Importance of methodology on $(99 \mathrm{~m})$ technetium dimercapto-succinic acid scintigraphic image quality: imaging pilot study for RIVUR (Randomized Intervention for Children With Vesicoureteral Reflux) multicenter investigation. J Urol. 2009; 182:272-9. [PubMed: 19450818]

17. Farhat W, Bägli DJ, Capolicchio G, et al. The dysfunctional voiding scoring system: quantitative standardization of dysfunctional voiding symptoms in children. J Urol. 2000; 164:1011-5. [PubMed: 10958730]

18. Benninga M, Candy DC, Catto-Smith AG, et al. The Paris Consensus on Childhood Constipation Terminology (PACCT) Group. J Pediatr Gastroenterol Nutr. 2005; 40:273-5. [PubMed: 15735478]

19. Performance standards for antimicrobial susceptibility testing: twenty-second informational supplement. Wayne, PA: Clinical and Laboratory Standards Institute; 2012.

20. Brandström P, Esbjörner E, Herthelius M, Swerkersson S, Jodal U, Hansson S. The Swedish reflux trial in children: III. Urinary tract infection pattern. J Urol. 2010; 184:286-91. [PubMed: 20488494]

21. Brandström P, Nevéus T, Sixt R, Stokland E, Jodal U, Hansson S. The Swedish reflux trial in children. IV. Renal damage. J Urol. 2010; 184:292-7. [PubMed: 20494369]

22. Subcommittee on Urinary Tract Infection, Steering Committee on Quality Improvement and Management. Urinary tract infection: clinical practice guideline for the diagnosis and management of the initial UTI in febrile infants and children 2 to 24 months. Pediatrics. 2011; 128:595-610. [PubMed: 21873693] 


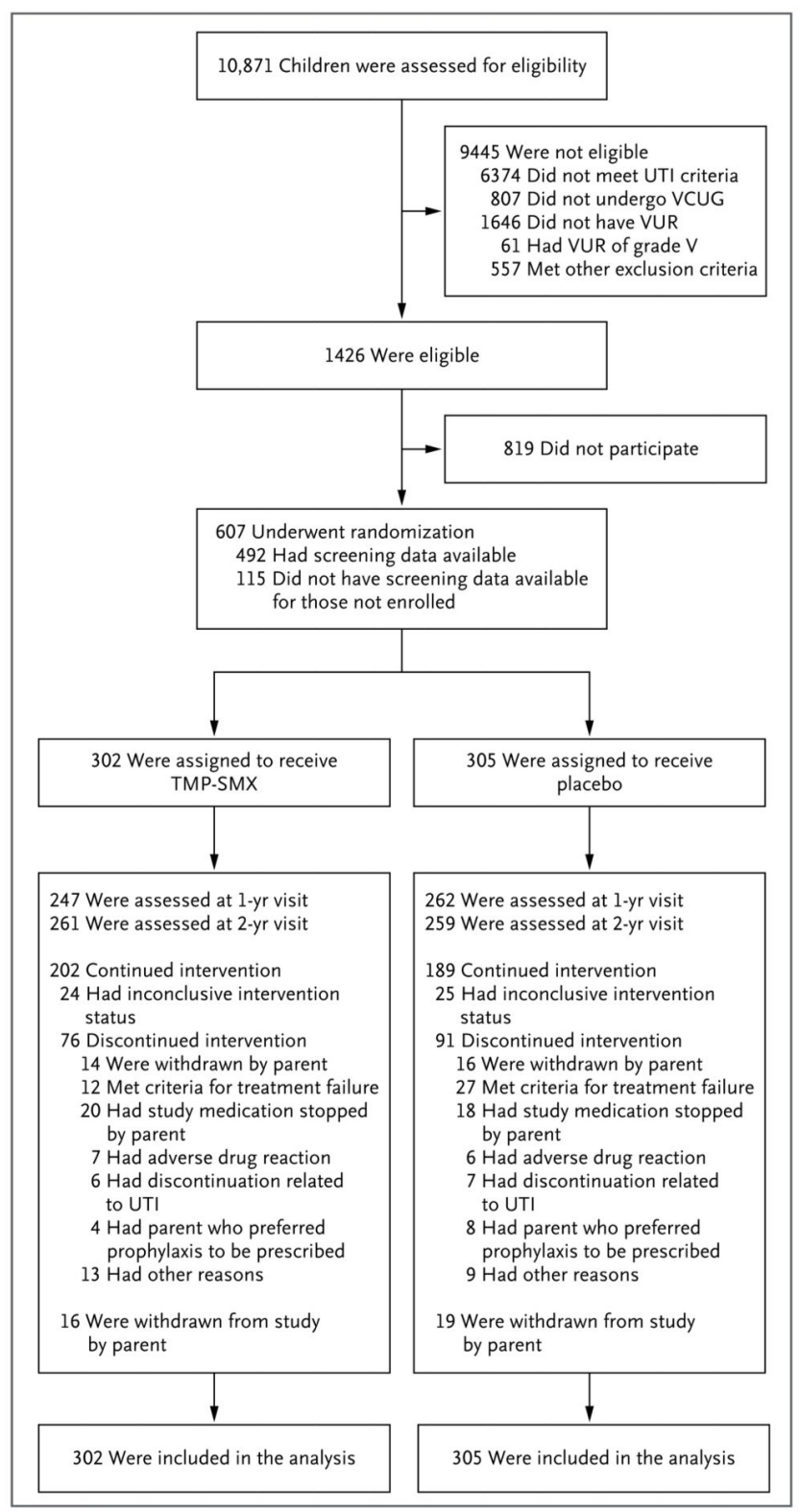

Figure 1. Enrollment, Randomization, and Follow-up of Children in the Trial Capture of screening data commenced in November 2007; children were enrolled at various clinical sites (emergency departments, radiology departments, and primary care, urology, and nephrology offices), resulting in diverse criteria for screening (abnormal urinalysis results, positive urine culture, and abnormal result of voiding cystourethrography [VCUG]). Enrollment of children commenced in June 2007; 115 eligible children were enrolled throughout the study without corresponding screening data for those not enrolled. Children who were withdrawn from the study by a parent include some children who discontinued the intervention because they met criteria for treatment failure or had a parent who preferred prophylaxis to be prescribed. TMP-SMX denotes trimethoprim-sulfamethoxazole, UTI urinary tract infection, and VUR vesicoureteral reflux. 


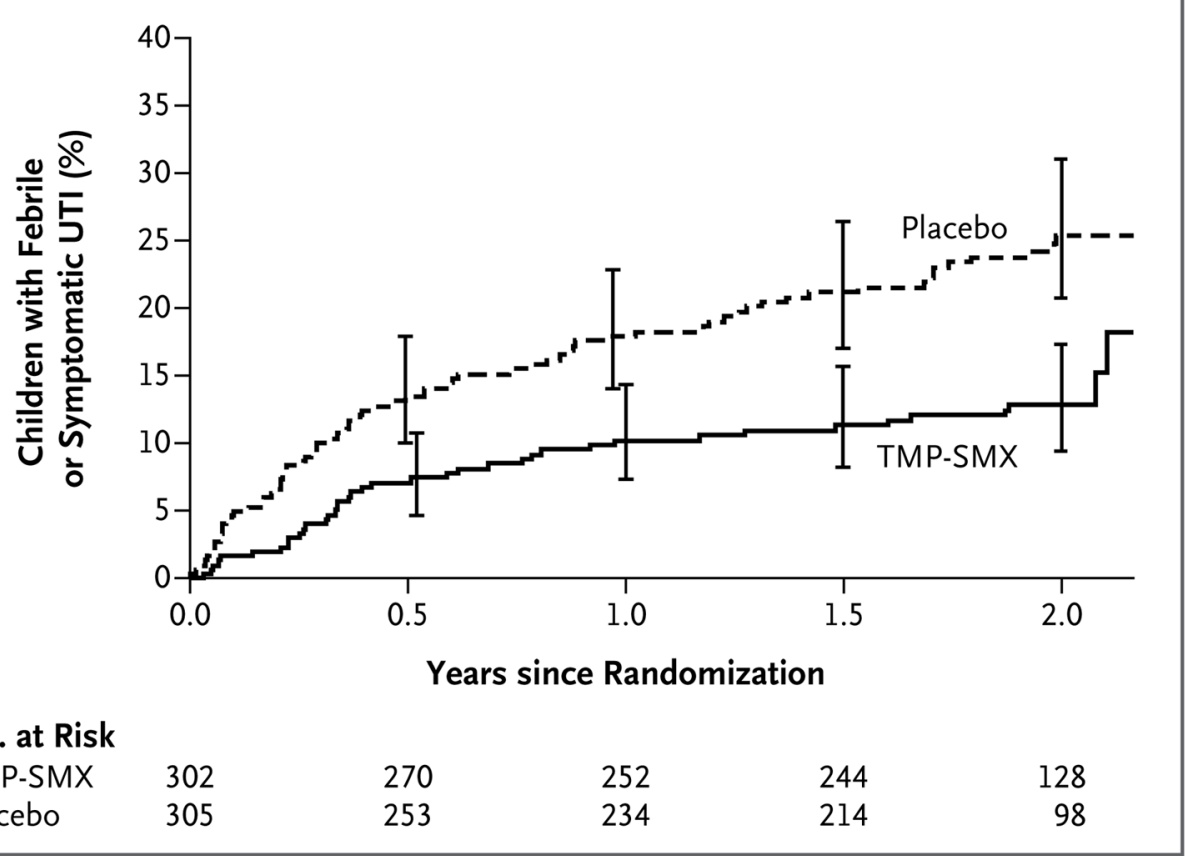

Figure 2. Time to First Recurrent Febrile or Symptomatic UTI

Shown are Kaplan-Meier estimates of the cumulative percentage of children who had a recurrent febrile or symptomatic UTI according to study group. Fewer children assigned to TMP-SMX prophylaxis had a UTI than children assigned to placebo $(\mathrm{P}<0.001$ by log-rank test). I bars indicate $95 \%$ confidence intervals. 


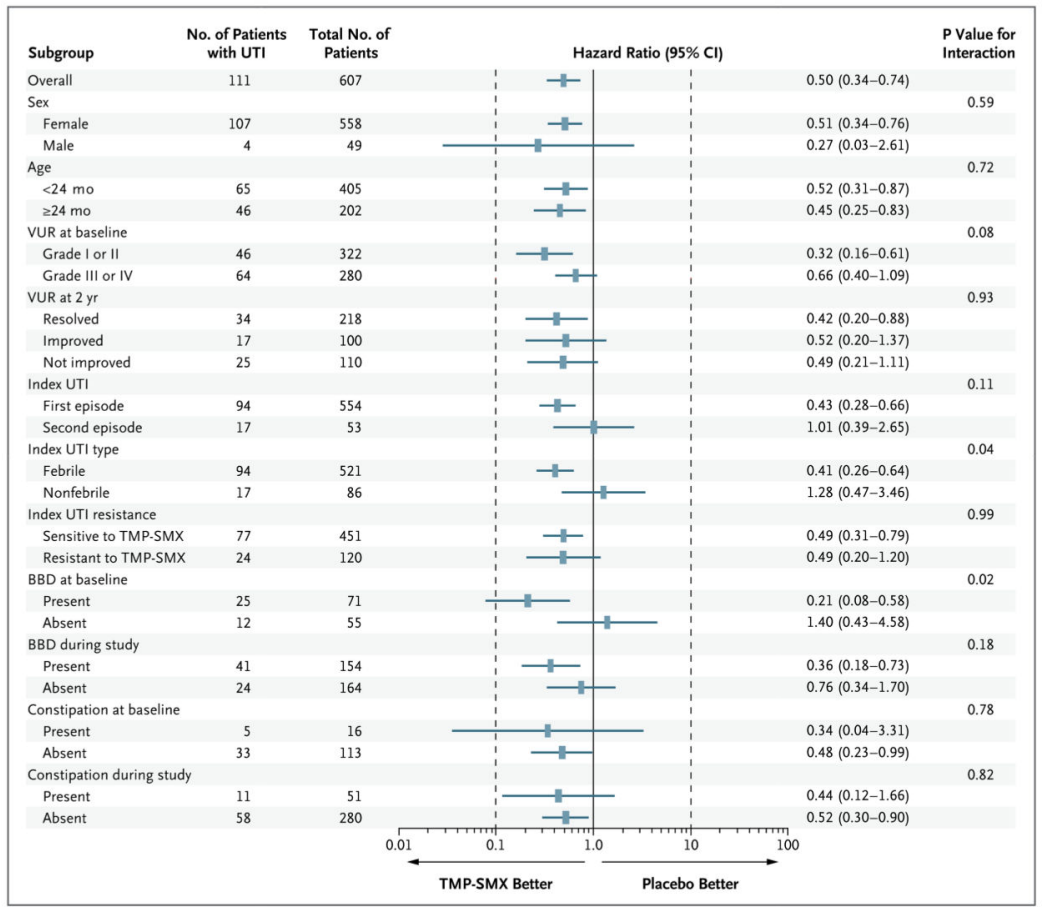

Figure 3. Effect of Antimicrobial Prophylaxis on the Risk of Febrile or Symptomatic UTI Depicted are hazard ratios (rectangles) and 95\% confidence intervals (horizontal lines) for a first recurrent febrile or symptomatic UTI overall and for subgroups. P values are based on Wald tests for the interaction of subgroup with study-group assignment. Hazard ratios of less than 1.00 indicate that the risk of a recurrent febrile or symptomatic UTI was lower among the children randomly assigned to antimicrobial prophylaxis than among those assigned to placebo. BBD denotes bladder and bowel dysfunction. 


\section{Table 1}

Baseline Demographic and Clinical Characteristics According to Study Group. ${ }^{*}$

\begin{tabular}{|c|c|c|c|}
\hline Characteristic & $\begin{array}{c}\text { Trimethoprim-Sulfamethoxazole }(\mathbf{N} \\
=302)\end{array}$ & Placebo $(\mathrm{N}=305)$ & Overall $(N=607)$ \\
\hline \multicolumn{4}{|l|}{ Age } \\
\hline Median - mo & 12 & 12 & 12 \\
\hline Interquartile range - mo & $5-31$ & $6-30$ & $6-31$ \\
\hline \multicolumn{4}{|l|}{ Group - no. $(\%)$} \\
\hline $2-11 \mathrm{mo}$ & $151(50.0)$ & $147(48.2)$ & $298(49.1)$ \\
\hline $12-23 \mathrm{mo}$ & $48(15.9)$ & $59(19.3)$ & $107(17.6)$ \\
\hline $24-35 \mathrm{mo}$ & $43(14.2)$ & $36(11.8)$ & $79(13.0)$ \\
\hline $36-72 \mathrm{mo}$ & $60(19.9)$ & $63(20.7)$ & $123(20.3)$ \\
\hline \multicolumn{4}{|l|}{ Sex - no. $(\%)$} \\
\hline \multicolumn{4}{|l|}{ Male } \\
\hline Circumcised & $11(3.6)$ & $7(2.3)$ & $18(3.0)$ \\
\hline Uncircumcised & $14(4.6)$ & $17(5.6)$ & $31(5.1)$ \\
\hline Female & 277 (91.7) & $281(92.1)$ & 558 (91.9) \\
\hline \multicolumn{4}{|l|}{ Race - no./total no. $(\%)^{\dagger}$} \\
\hline White & $245 / 298(82.2)$ & $237 / 299(79.3)$ & $482 / 597(80.7)$ \\
\hline Black & $10 / 298(3.4)$ & $17 / 299(5.7)$ & $27 / 597(4.5)$ \\
\hline Multiracial & $20 / 298(6.7)$ & $20 / 299(6.7)$ & $40 / 597(6.7)$ \\
\hline Other & $23 / 298(7.7)$ & $25 / 299(8.4)$ & 48/597 (8.0) \\
\hline Hispanic ethnic group - no./total no. $(\%)^{\dagger}$ & $31 / 300(10.3)$ & $46 / 304(15.1)$ & $77 / 604(12.7)$ \\
\hline \multicolumn{4}{|c|}{ Educational level of primary caregiver - no./total no. (\%) } \\
\hline High-school graduate or lower & $78 / 299(26.1)$ & $80 / 303(26.4)$ & $158 / 602(26.2)$ \\
\hline Some college or 2-yr degree & $78 / 299(26.1)$ & $78 / 303(25.7)$ & $156 / 602(25.9)$ \\
\hline College graduate or higher & $143 / 299(47.8)$ & $145 / 303(47.9)$ & $288 / 602(47.8)$ \\
\hline \multicolumn{4}{|l|}{ Health insurance - no./total no. $(\%)$} \\
\hline Commercial & $228 / 299(76.3)$ & $211 / 302(69.9)$ & $439 / 601(73.0)$ \\
\hline Public ${ }^{\dagger}$ & $71 / 299(23.7)$ & $91 / 302(30.1)$ & $162 / 601(27.0)$ \\
\hline \multicolumn{4}{|l|}{ Index UTI — no. $(\%)$} \\
\hline First episode & $275(91.1)$ & $279(91.5)$ & $554(91.3)$ \\
\hline Second episode & $27(8.9)$ & $26(8.5)$ & $53(8.7)$ \\
\hline Febrile only & $96(31.8)$ & $100(32.8)$ & $196(32.3)$ \\
\hline Symptomatic only & $49(16.2)$ & $37(12.1)$ & $86(14.2)$ \\
\hline Febrile and symptomatic & $157(52.0)$ & $168(55.1)$ & $325(53.5)$ \\
\hline \multicolumn{4}{|l|}{$\begin{array}{l}\text { Susceptibility of index UTI to trimethoprim- } \\
\text { sulfamethoxazole- no./total no. }(\%)\end{array}$} \\
\hline $\operatorname{Resistant} \S$ & $55 / 278(19.8)$ & $65 / 293(22.2)$ & $120 / 571(21.0)$ \\
\hline Sensitive & $223 / 278(80.2)$ & $228 / 293(77.8)$ & $451 / 571(79.0)$ \\
\hline
\end{tabular}




\begin{tabular}{|c|c|c|c|}
\hline Characteristic & $\begin{array}{c}\text { Trimethoprim-Sulfamethoxazole }(\mathrm{N} \\
=\mathbf{3 0 2})\end{array}$ & Placebo $(\mathbf{N}=305)$ & Overall $(\mathbf{N}=607)$ \\
\hline Bladder and bowel dysfunction - no./total no. $(\%)^{q l}$ & $34 / 63(54.0)$ & $37 / 63(58.7)$ & $71 / 126(56.3)$ \\
\hline Constipation — no./total no. $(\%) \|$ & $8 / 65(12.3)$ & $8 / 64(12.5)$ & $16 / 129(12.4)$ \\
\hline \multicolumn{4}{|l|}{ Ultrasound abnormalities — no./total no. (\%) } \\
\hline Hydronephrosis ${ }^{* *}$ & $19 / 300(6.3)$ & $13 / 302(4.3)$ & $32 / 602(5.3)$ \\
\hline Ureter duplication & $18 / 300(6.0)$ & $15 / 302(5.0)$ & $33 / 602(5.5)$ \\
\hline \multicolumn{4}{|c|}{ Highest degree of vesicoureteral reflux - no./total no. $(\%)^{\dagger \dagger}$} \\
\hline Grade I & 35/301 (11.6) & 33/301 (11.0) & 68/602 (11.3) \\
\hline Grade II & $123 / 301(40.9)$ & $131 / 301(43.5)$ & $254 / 602(42.2)$ \\
\hline Grade III & $118 / 301(39.2)$ & $112 / 301(37.2)$ & $230 / 602(38.2)$ \\
\hline Grade IV & $25 / 301(8.3)$ & $25 / 301(8.3)$ & $50 / 602(8.3)$ \\
\hline Bilateral vesicoureteral reflux — no./total no. (\%) & $146 / 300(48.7)$ & $141 / 300(47.0)$ & $287 / 600(47.8)$ \\
\hline \multicolumn{4}{|l|}{ Renal scarring - no./total no. $(\%)^{\text {ft }}$} \\
\hline None & 280/292 (95.9) & $281 / 290(96.9)$ & $561 / 582(96.4)$ \\
\hline Mild & $1 / 292(0.3)$ & $0 / 290$ & $1 / 582(0.2)$ \\
\hline Moderate & $3 / 292(1.0)$ & $2 / 290(0.7)$ & $5 / 582(0.9)$ \\
\hline Severe & 4/292 (1.4) & $2 / 290(0.7)$ & $6 / 582(1.0)$ \\
\hline Global atrophy & $4 / 292(1.4)$ & $5 / 290(1.7)$ & $9 / 582(1.5)$ \\
\hline
\end{tabular}

* There were no significant differences between the study groups in any of the baseline characteristics $(\mathrm{P}>0.05)$. UTI denotes urinary tract infection.

${ }^{\dagger}$ Race and ethnic group were reported by the parent or guardian.

Four children with no insurance were classified as having public insurance.

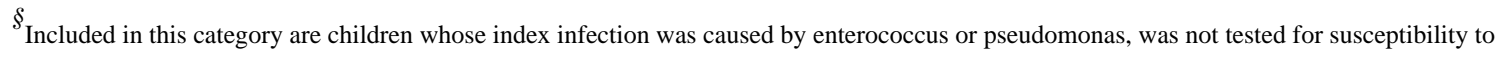
trimethoprim-sulfamethoxazole, and was assumed to be resistant and children whose index infection was caused by bacteria that were resistant to trimethoprim but were not tested for susceptibility to sulfamethoxazole.

II Bladder and bowel dysfunction was defined as a score of more than 6 for toilet-trained girls and more than 9 for toilet-trained boys on a modified Dysfunctional Voiding Scoring System. ${ }^{17}$ Scores range from 0 to 30 , with higher scores indicating greater bladder and bowel dysfunction.

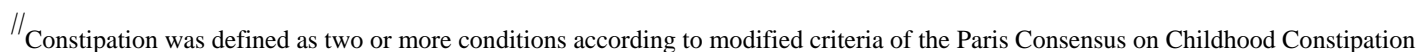
Terminology Group ${ }^{18}$ ( $<3$ bowel movements per week, $>1$ episode of fecal incontinence per week, passage of a large stool that obstructed the toilet, retentive posture and behavior, and pain during defecation).

**

All 32 children had hydronephrosis of less than grade 4 on the Society for Fetal Urology scale.

${ }^{\dagger \dagger}$ Seven children with central assessment of no vesicoureteral reflux were included in grade I, and one child with central assessment of grade $\mathrm{V}$ was included in grade IV (with enrollment based on local readings). Data on voiding cystourethrography for five children were missing because images were not available for central evaluation.

${ }^{*}$ A total of 25 children did not undergo renal scanning with technetium- $99 \mathrm{~m}$-labeled dimercaptosuccinic acid at baseline. Among 98 children (40 in the trimethoprim-sulfamethoxazole group and 58 in the placebo group) in whom scanning was performed less than 31 days after the index UTI, scarring was identified in 1 child in the trimethoprim-sulfamethoxazole group. All other instances of scarring were identified in the 484 children (252 in the trimethoprim-sulfamethoxazole group and 232 in the placebo group) in whom scanning was performed between 31 and 112 days after the index UTI. 


\section{Table 2}

\section{Clinical Outcomes According to Study Group.}

\begin{tabular}{|c|c|c|c|}
\hline \multirow[t]{2}{*}{ Outcome } & Trimethoprim-Sulfamethoxazole & Placebo & $\begin{array}{l}\text { Absolute Difference in Risk }(95 \% \\
\text { CI) }\end{array}$ \\
\hline & \multicolumn{2}{|c|}{ no. of children/total no. (\%) } & percentage points \\
\hline \multicolumn{4}{|l|}{ Recurrent febrile or symptomatic UTI ${ }^{*}$} \\
\hline $\begin{array}{l}\text { Children with missing 2-yr data classified } \\
\text { as having had an event (intention-to- treat } \\
\text { analysis) }\end{array}$ & $77 / 302(25.5)$ & $114 / 305(37.4)^{\dagger}$ & $11.9(4.6$ to 19.2$)$ \\
\hline $\begin{array}{l}\text { Children with missing } 2 \text {-yr data classified } \\
\text { as not having had an event (intention-to-treat } \\
\text { analysis) })^{\frac{1}{5}}\end{array}$ & $39 / 302(12.8)$ & $72 / 305(25.4)^{\S}$ & $12.6(6.1$ to 19.0$)$ \\
\hline Children with missing 2-yr data omitted & $39 / 264(14.8)$ & $72 / 263(27.4)^{\S}$ & $12.6(5.7$ to 19.5$)$ \\
\hline Treatment failure $\stackrel{\ddagger}{\ddagger} /$ & $14 / 302(5.0)$ & $27 / 305(9.6) \|$ & $4.5(0.2$ to 8.8$)$ \\
\hline \multicolumn{4}{|l|}{ Renal scarring ${ }^{* *}$} \\
\hline Overall & 27/227 (11.9) & $24 / 235(10.2)$ & $-1.7(-7.4$ to 4.0$)$ \\
\hline Severe ${ }^{\dagger \dagger}$ & $9 / 227(4.0)$ & $6 / 235(2.6)$ & $-1.4(-4.7$ to 1.8$)$ \\
\hline Newtt & $18 / 220(8.2)$ & $19 / 227(8.4)$ & $0.2(-4.9$ to 5.3$)$ \\
\hline Any cortical defect & 29/227 (12.8) & 25/235 (10.6) & $-2.1(-8.0$ to 3.7$)$ \\
\hline \multicolumn{4}{|l|}{ Antimicrobial resistance } \\
\hline Resistant Escherichia coli in stool & $56 / 203(27.6)$ & $41 / 210(19.5)$ & $-8.1(-16.2$ to 0.1$)$ \\
\hline $\begin{array}{l}\text { First recurrent febrile or symptomatic UTI } \\
\text { with resistant E. coli }\end{array}$ & $19 / 30(63.3)^{\S \S}$ & $11 / 57(19.3)$ & $-44.0(-64.1$ to -24.0$)$ \\
\hline $\begin{array}{l}\text { First recurrent febrile or symptomatic UTI } \\
\text { with any resistant pathogen }\end{array}$ & $26 / 38(68.4)^{\S \S}$ & $17 / 69(24.6)$ & $-43.8(-61.7$ to -25.8$)$ \\
\hline
\end{tabular}

* Included are 7 children ( 3 in the trimethoprim-sulfamethoxazole group and 4 in the placebo group) with febrile or symptomatic UTIs that occurred before a missed 2-year visit. Imputation was applied to 38 children in the trimethoprim-sulfamethoxazole group and 42 children in the placebo group.

${ }^{\dagger} \mathrm{P}=0.002$ by log-rank test stratified according to five core sites.

†Percentages are based on Kaplan-Meier 2-year estimates.

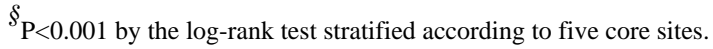

${ }^{I I}$ Treatment failure was defined as the occurrence of two febrile UTIs (28 children), one febrile UTI and three symptomatic UTIs ( 2 children), four symptomatic UTIs ( 2 children), or new or worsening renal scarring ( 9 children).

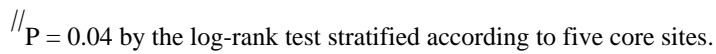

Renal scarring was defined as a decreased uptake of tracer that was associated with loss of contours or the presence of cortical thinning. 
${ }^{\dagger \dagger}$ Severe renal scarring was defined as scarring in more than 4 of 12 segments in at least one kidney or global atrophy characterized by a diffusely scarred and shrunken kidney.

New renal scarring was defined as scarring on the outcome renal scan with technetium-99m-labeled dimercaptosuccinic acid that was not present at baseline.

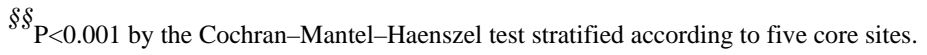

